\title{
The Impacts of Elastic Band Training on the Posterior Abdominal Wall Muscles of Olympic-Style Weightlifters
}

\author{
Kenan Erdağ ${ }^{1}$, Necdet Poyraz ${ }^{2}$, Sadullah Bahar ${ }^{3}$, Bülent Işık ${ }^{4}$, Hüseyin Aslan ${ }^{5}$ \\ ${ }^{1}$ Necmettin Erbakan University, Faculty of Education, Physical Education and Sports Department, Konya, Turkey \\ ${ }^{2}$ Necmettin Erbakan University, Meram Faculty of Medicine, Radiology Department, Konya, Turkey \\ ${ }^{3}$ Selcuk University, Veterinary Faculty, Anatomy Department, Konya, Turkey \\ ${ }^{4}$ Provincial Health Directorate, Konya, Turkey \\ ${ }^{5}$ Faculty of Sport Sciences, Selcuk University, Konya, Turkey \\ Correspondence: Kenan Erdağı, Necmettin Erbakan University, Faculty of Education, Physical Education and Sports \\ Department, Konya, Turkey.
}

Received: March 18, 2019

doi:10.11114/jets.v7i5.4148

\author{
Accepted: April 17, 2019 \\ Online Published: April 22, 2019 \\ URL: https://doi.org/10.11114/jets.v7i5.4148
}

\begin{abstract}
Purpose: In this study, it was aimed to examine the impacts of elastics band trainings, which were applied for 12 weeks on the Olympic-style weightlifters, on their sportive performances and psoas, ilacus, and quadratus lumborum muscle volumes.

Materials and Methods: This research study was conducted on 4 groups, comprising of 12 men (elastic band training group ( $\mathrm{n}=6)$, control group $(\mathrm{n}=6)$ ), and 12 women (elastic band training group $(\mathrm{n}=6)$, control group $(\mathrm{n}=6)$ ) Olympic-style weightlifters. The athletes in the elastic band training groups were engaged in standing hip flexion exercises, clamshell exercises, lying hip flexion exercises, and side bend exercises. Before and after the elastic band training applied to the Olympic-style weightlifters for 12 weeks, (1.5 Tesla) MRI device was used for the axial images of the regions starting from the $12^{\text {th }}$ thoracic vertebrae to the trochanter minor of femur. The volume calculations of the muscles were conducted via the Cavalieri method.
\end{abstract}

Results: After the elastic band training, it was determined that the total volume of posterior abdominal wall muscles of the men and women weightlifters in the elastic band training groups and the total weights lifted by them were higher compared to those of the control group individuals $(\mathrm{p}<0,001)$.

Conclusion: As the result, it can be stated that including the posterior abdominal wall muscle developing trainings into the general programs of the weightlifters in the Olympic weightlifting sport can both enable an increase in the volumes of the muscles in this region and positively influence the performance of the athletes.

Keywords: Olympic weightlifting, M. psoas, M. quadratus lumborum, M. iliacus, Elastic band training

\section{Introduction}

The muscles of lumbar region are grouped according to their anatomical locations and functions. Psoas (PS), quadratus lumborum (QL), and iliacus (IL) muscles, which are found in paramedian position at anterolateral of the lumbar spine, are called as the posterior abdominal wall muscles (Williams and Warwick, 1992; Arınc1 and Elhan, 2001). The posterior abdominal wall muscles, which help the load to be distributed in balance to the lumbo pelvic region during static and dynamic functions such as walking, running, upright posture, frontal and lateral bending, and weight lifting, have important roles in controlling the lumbar lordosis and stabilization of lumbar spine and hip (Nachemson, 1966; Bogduk et al., 1992, Jemmett et al., 2004).

In Olympic weightlifting sport (OW), where lumbopelvic-stability is dominant, serious injuries might result from high-level dynamic forcing, overload in the lumbar region, and muscle weaknesses in the same region (Garhammer, 1985; Garhammer, 1991). In the dynamic or static loading time periods, during which the weights are lifted, it is related with the power of the muscles for the lumbar region to stay healthy (Greene et al., 2001).

There is a positive relationship between the increase in muscle power and the increase in the cross-sectional area (Gündüz, 1997). It is reported that power trainings conducted with different types of trainings and equipments increased 
the cross-sectional area and volume, and this increase developed the power and strength parameters in a positive way (Mendis and Hides, 2016; Ince 2019; Jelena et al., 2009; Abe et al., 2010; Morse et al., 2005). Elastic bands (E-Band) are one of the equipment that develop the strength (Page and Ellenbecker, 2005). E-Bands are the equipment that are mostly used for increasing the sportive performance (Treiber et al., 1998; Janusevicius etal., 2017), rehabilitation of the orthopedic problems in the elderly (Hintermeister et al., 1998; Kwak et al., 2016; Oh et al., 2016), and to prevent the decrease in the muscle power (Mikesky et al., 1994; Yasuda et al., 2014).

No study could be found which is conducted on determining the impacts of E-Band trainings on the PS, QL, IL muscle volumes and sportive performances of Olympic-style weightlifters (O-sW).

This research study aimed at examining the impacts of elastic band trainings, which was applied for 12 weeks to the $\mathrm{O}-\mathrm{sW}$, on their posterior abdominal muscles and performances.

\section{Material and Method}

\section{Subjects}

This research study was conducted on 4 groups, comprising of 12 men (E-Band training group (n=6), control group $(n=6)$ ), and 12 women (E-Band training group $(n=6)$, control group $(n=6)) O-s W$, who were between 18-24 years old, had been regularly and actively doing trainings in the last 3 years, were randomly grouped, and attended national and international competitions. The pre-training and post-training demographic data of the groups are presented in Table 1.

Table 1. Age and other body morphometric features of the research groups (Mean \pm SD)

\begin{tabular}{|c|c|c|c|c|c|c|c|c|c|c|c|c|}
\hline \multirow{3}{*}{$\begin{array}{l}\text { Morphometric } \\
\text { Features }\end{array}$} & \multicolumn{6}{|c|}{ Men } & \multicolumn{6}{|c|}{ Women } \\
\hline & \multicolumn{2}{|c|}{ Pre } & & \multicolumn{2}{|c|}{ Post } & \multirow[b]{2}{*}{$\mathbf{p}$} & \multicolumn{2}{|c|}{ Pre } & \multirow[b]{2}{*}{$\mathbf{p}$} & \multicolumn{2}{|c|}{ Post } & \multirow[b]{2}{*}{$\mathbf{p}$} \\
\hline & $\begin{array}{c}\text { E-Band } \\
n=6\end{array}$ & $\begin{array}{c}\text { Control } \\
n=6\end{array}$ & & $\begin{array}{c}\text { E-Band } \\
n=6\end{array}$ & $\begin{array}{c}\text { Control } \\
n=6\end{array}$ & & $\begin{array}{c}\text { E-Band } \\
n=6\end{array}$ & $\begin{array}{c}\text { Control } \\
n=6\end{array}$ & & $\begin{array}{c}\text { E-Band } \\
n=6\end{array}$ & $\begin{array}{c}\text { Control } \\
n=6\end{array}$ & \\
\hline Age (years) & $19 \pm 2,5$ & $19 \pm 2,5$ & 0,999 & $19 \pm 2,5$ & $19 \pm 2,5$ & 0,999 & $18,8 \pm 1$ & $19,5 \pm 1,4$ & 0,360 & $18,8 \pm 1$ & $19,5 \pm 1,4$ & 0,360 \\
\hline Heigl & $172,5 \pm 7,5$ & $172,7 \pm 4,6$ & 0,960 & $173 \pm 7,7$ & $173 \pm 4,8$ & 0,999 & $160,7 \pm 6$ & $159,8 \pm 6,4$ & 0,820 & $161,7 \pm 5,8$ & $160,7 \pm 6$ & 0,770 \\
\hline BW (kg) & $78,1 \pm 17,6$ & $80,1 \pm 14,4$ & 0,830 & $77,8 \pm 17,2$ & $80,1 \pm 14,6$ & 0,810 & $59,6 \pm 7,4$ & $58,6 \pm 6,1$ & 0,800 & $59,3 \pm 7,4$ & $58,3 \pm 5,8$ & 0,810 \\
\hline BMI $\left(\mathrm{kg} / \mathrm{m}^{2}\right)$ & $26,2 \pm 5,5$ & $26,9 \pm 4,7$ & 0,830 & $25,8 \pm 5,5$ & $26,5 \pm 4,8$ & 0,800 & $23,3 \pm 2,4$ & $23 \pm 2,2$ & 0,840 & $22,6 \pm 2,3$ & $22,6 \pm 2$ & 0,990 \\
\hline $\operatorname{BSA}\left(\mathbf{m}^{2}\right)$ & $1,9 \pm 0,2$ & $1,9 \pm 0,2$ & 0,800 & $1,9 \pm 0,2$ & $1,9 \pm 0,2$ & 0,810 & $1,6 \pm 0,1$ & $1,6 \pm 0,1$ & 0,750 & $1,6 \pm 0,1$ & $1,6 \pm 0,1$ & 0,770 \\
\hline
\end{tabular}

BW: Body weight, BMI: Body mass index, BSA: Body surface area, Pre: Before e-band training, Post: After e-band training.

\subsection{Procedure and Training Program}

Ethical Committee Approval Documents concerning the study was gained from the K.T.O. Karatay University, Medical Faculty, Department of Medical Education Ethical Committee, and all of the procedures were performed according to this document (date:12-04-2016 and numbered 017). A specialist physician performed physical inspections of the athletes, and necessary explanations concerning the content of the study was made to the athletes.

$\mathrm{O}$-sW trainings were applied at the same volume and intensity to all of the groups throughout the 12-weeks period, and 6 days a week. OW trainings contained snatch, power snatch, clean-and-jerk, jerk push, jerk power clean, snatch pulls, clean pulls, squat front, and squatback (Badıllo et al., 2006). Before the E-Band trainings and at the end of the 12th week, all of the participant weightlifters were included in the regional competitions. The athletes were given 3 trials for snatch and clean -and-jerk movements in the competitions. The best single repeat maximal weights that were lifted by the groups through snatch, clean-and-jerk, and in total were recorded and presented in Table 5 as comparisons.

Since the resistance produced by the E-Bands change according to their colors (Page and Ellenbecker, 2005), in order to determine the colors of the E-Bands that the training group athletes will use, the participants were made to perform training movements (15 reps) with E-Bands in different colors. It was observed that athletes from the E-Band training group, who made the movements in the most accurate way and without changing the angle, used the black E-Bands (Theraband, Hygenic Corporation, Akron, OH, USA). The E-Bands were replaced with new ones in case of deformation or a decrease in their resistance (Santos et al., 2009).

Only the men/women athletes from the E-Band training groups were made to perform E-Band trainings in addition to and after each OW training. In this time period, except for the OW trainings, the men/women athletes from the control groups were not made to perform any E-Band training, specific training, or placebo. E-Band training planning was comprised of warm-up (10 min), E-Band training $(20 \mathrm{~min})$, cooling down and stretching $(10 \mathrm{~min})$. Following the warm-up, E-Band trainings were conducted by the athletes for 12 weeks (6 days a week) and in 4 sets of 15 reps, with one-minute intervals in between each set (Table 2). For the E-Band training group, standing hip flexion exercises (Figure 1) clamshell exercises (Figure 2), and lying hip flexion exercises (Figure 3) (Johnston et al., 1999; Johnson and Reid, 1991; Anderson et al., 1995) were applied with E-Band for the iliopsoas muscle compartment, which works actively with hip flexion and hip abduction; and sideband exercises were applied with E-Band for the quadratus lumborum muscle, which works actively with the lateral flexion of the trunk (Figure 4) (McGill et al., 1996). 
Table 2. Weekly E-Band exercise program applied to the men and women groups

\begin{tabular}{|c|c|c|c|c|c|c|}
\hline \multirow{2}{*}{ Day } & \multirow{2}{*}{ E-Band Exercise } & \multirow{2}{*}{ Repeat } & \multirow{2}{*}{ Sets } & \multirow{2}{*}{$\begin{array}{c}\text { Rest } \\
\text { (minute) }\end{array}$} & \multirow{2}{*}{$\begin{array}{c}1 \text { week } \\
\text { Total Repeat }\end{array}$} & \multirow{2}{*}{$\begin{array}{c}12 \text { week } \\
\text { Total Repeat }\end{array}$} \\
\hline & & & & & & \\
\hline \multirow{2}{*}{1} & Standing hip flexion & 15 & 4 & 1 & 60 & 720 \\
\hline & Clamshell exercises & 15 & 4 & 1 & 60 & 720 \\
\hline \multirow{2}{*}{2} & Lying hip flexion & 15 & 4 & 1 & 60 & 720 \\
\hline & Side bend & 15 & 4 & 1 & 60 & 720 \\
\hline \multirow{2}{*}{3} & Standing hip flexion & 15 & 4 & 1 & 60 & 720 \\
\hline & Clamshell exercises & 15 & 4 & 1 & 60 & 720 \\
\hline \multirow{2}{*}{4} & Lying hip flexion & 15 & 4 & 1 & 60 & 720 \\
\hline & Side bend & 15 & 4 & 1 & 60 & 720 \\
\hline \multirow{2}{*}{5} & Standing hip flexion & 15 & 4 & 1 & 60 & 720 \\
\hline & Clamshell exercises & 15 & 4 & 1 & 60 & 720 \\
\hline \multirow{2}{*}{6} & Lying hip flexion & 15 & 4 & 1 & 60 & 720 \\
\hline & Side bend & 15 & 4 & 1 & 60 & 720 \\
\hline
\end{tabular}

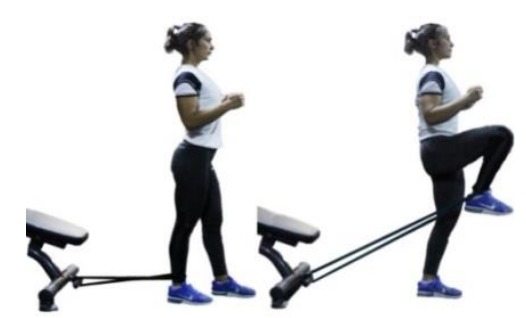

Figure1. Standing hip flexion exercises

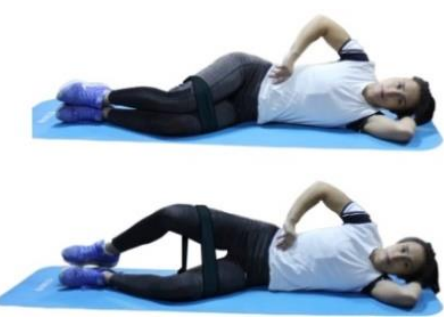

Figure 2. Clamshell exercises

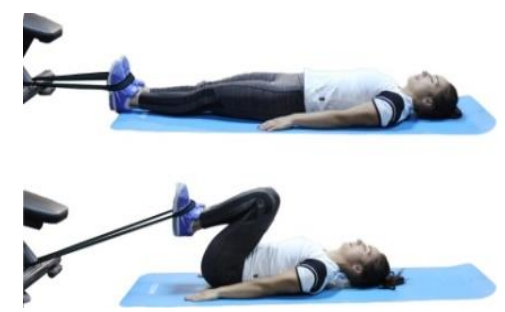

Figure 3. Lying hip flexion exercises

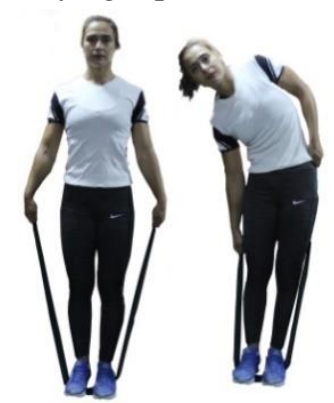

Figure 4. Side bend exercises 


\subsection{MRI Protocol}

In the abdomen imaging of the research groups, the (1.5 Tesla) magnetic resonance imaging (MRI) (MagnetomAvanto; Siemens Healthcare Erlangen, Germany) device was used. The volunteers positioned on the MR table in a supine posture with the legs fully extended. Four channel phased array body coils were placed on the abdominal region and the preparations were completed for MR imaging test. The region to be imaged in the study was determined as the proximal border of the $12^{\text {th }}$ Thoracic vertebrae, and distal border of trochanter minor of femur. Axial images were taken from the relevant region (T1 parameters: TE: 10, TR:1150, Cross section thickness: $5 \mathrm{~mm}$, Interslice distance: $5 \mathrm{~mm}$, Matrix: $320 * 160$, FOV: $206 * 330$, NEX: 2), and sagittal and coronal images were taken for use in radiological evaluations. Imaging process concerning the groups was completed after recording the MR images to the CD-ROMs in DICOM format.

\subsection{MRI Evaluation}

A radiologist evaluated the MR images of posterior abdominal wall muscles of all the groups before the research and after the E-Band training, which lasted for 12 weeks. The axial cross-sectional views, which included the relevant muscle images, were detected in the CD-ROMs opened in the personal computers. After being named from proximal to distal and exported in JPEG format, these images were recorded to the files created for each participant. The axial views of each participant were opened in the image analysis program (Corel Designer Technical Suite X5). The muscle borders in the images were determined and recorded by using graphics tablet (Uc-logic LapazzA4 professionally designed tablet, Japan) (Figure 5).

\subsection{Calculation of the Muscle Volumes}

Cavalieri method was used in determining the volumes of the muscles. Previous research studies were taken as reference (Gundersen and Jensen, 1987; Canan et al., 2002; Sahin et al., 2003) in using this method. In the Cavalieri method, the researchers can question the accuracy of their volume calculations, which were determined by taking the cross-sections and counting the points, by an error coefficient (EC) calculation. If the calculated EC value is equal or lower than 0.05, it demonstrates that the volume calculation is accurate (Gundersen and Jensen ,1987; Sahin et al., 2003; Bahar et al., 2014). Before a volume calculation with the Cavaileri method, a prestudy is conducted on the number of the cross-sections and on determining the frequency of the points on the point grids, which will be used in calculating projection areas of the relevant structures. At the end of the prestudy, which aims a volume calculation with a $\mathrm{HK} \leq 0.05$ value; it was decided that, in muscle volume calculation of QL and IL, all of the cross-sectional images will be used; as per the muscle volume calculation of PS, it was decided to reduce by half the number of the cross-sections after a $1 / 2$ systematic random sampling; and it was decided about the point grids that, the point grids, in which the surface of a point represents an area of $36 \mathrm{~mm}^{2}$, will be used for men, and the ones, in which the surface of a point represents an area of $25 \mathrm{~mm}^{2}$, will be used for women. After the prestudy, the image files recorded separately for each participant were opened via ImageJ program and after necessary synchronizations, the decided point grids were thrown randomly upon the images. The points falling to the mentioned muscles were (left and right separately) counted (Figure 6). This transaction was repeated for each muscle, and the number of the total points $(\Sigma p)$ falling to the muscle was determined. This figure was multiplied with the area represented by the points ( 36 for the men groups, and 25 for thewomen groups); thus, the total cross-sectional area $(\Sigma \mathrm{A})$ of the muscles was calculated. The volumes of the muscles were calculated via the following mathematical formula, $\mathrm{V}=\mathrm{t} \times \Sigma \mathrm{A}$ ( $\mathrm{t}$ : distance between two cross-sectional images, $\Sigma \mathrm{A}$ : total muscle cross-sectional area). EC calculation concerning the volume calculation was conducted taking the previous studies (Gundersen and Jensen, 1987; Canan et al., 2002; Sahin et al., 2003) as the reference. 


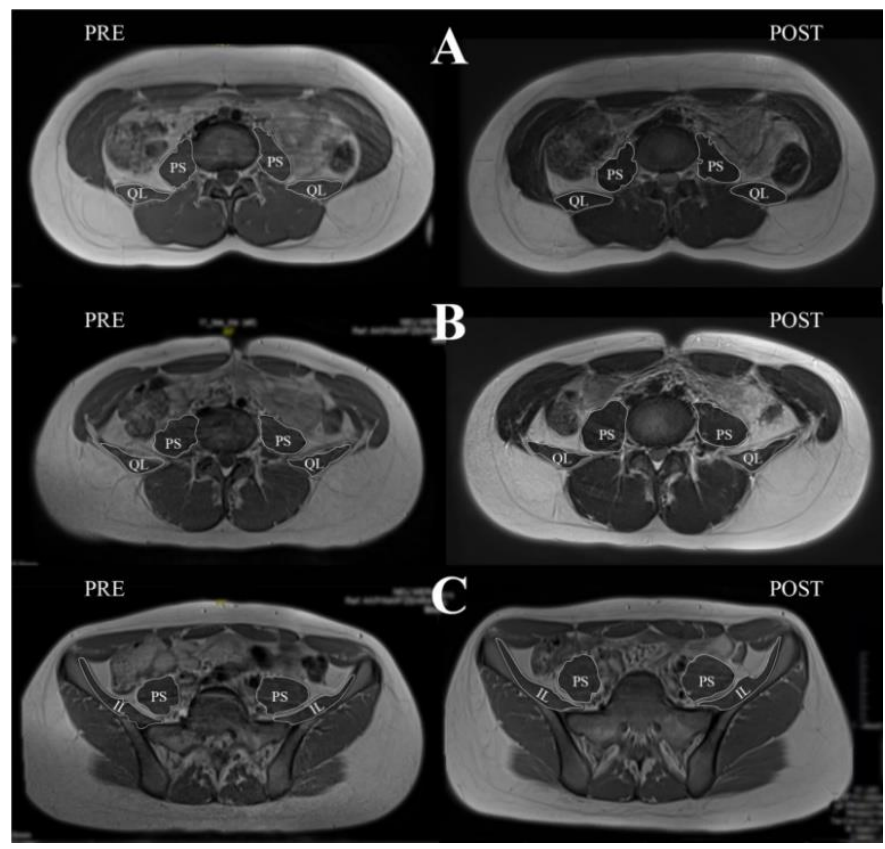

Figure 5. Pre and post E-Band training posterior abdominal wall muscle borders on axial cross-sections. A; image taken from $\mathrm{L}_{3}-\mathrm{L}_{4}, \mathrm{~B}$; image taken from $\mathrm{L}_{4}-\mathrm{L}_{5}$ intervertebral disc and $\mathrm{C}$; image taken from $\mathrm{S}_{2}$ vertebra level. $\mathrm{PS} ; \mathrm{m}$. psoas major.IL; m. iliacus, QL; m. quadratus lumborum

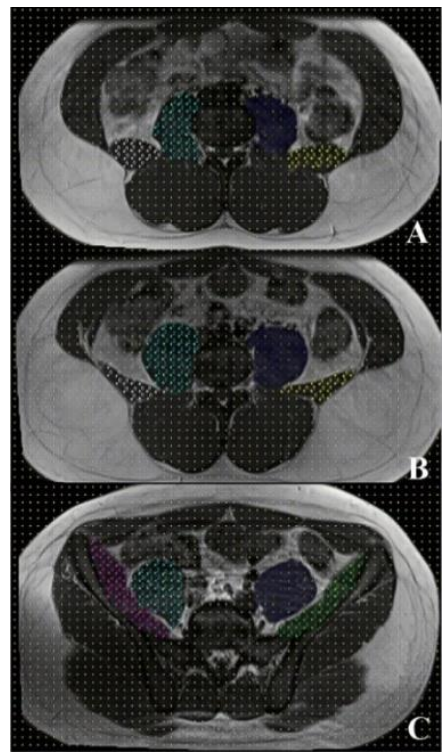

Figure 6. Throwing point grids upon MR images, and determining the points fallen to the muscles, in the ImageJ program. The image is taken from A; L3-L4, B; L4-L5 intervertebral disc and C; S2 vertebra levels

\section{Statistical Analysis}

SPPS 25 statistics package program (IBM Corp. Released 2017. IBM SPSS Statistics for Windows, Version 25.0. Armonk, NY: IBM Corp.) was used for the analysis of the data obtained from the study. The variables were evaluated after the normality test and the pre-conditions of homogeneity of the variances (Shapiro Wilk and Levene Test) were conducted. During the data analysis, independent two-sample t-test (Student's t-test) was used for the comparison of the two groups, and dependent two-sample t-test (Paired t-test) was used for the evaluation of pre and post training. P $<0.05$ and $\mathrm{p}<0.001$ were considered for the significance levels of the tests. The results were presented as a chart in the form of Mean \pm SD.

\section{Results}

The age, height, weight, body surface area, and body mass index data of the research groups were shown on Table 1 . At the outset of the E-Band trainings and at the end of the E-Band trainings, which lasted for 12 weeks, the groups were 
compared in terms of these parameters and no statistical difference was observed $(\mathrm{P}>0,05)$.

It was detected that standing hip flexion exercises, clamshell exercises, lying hip flexion exercises and side bend exercises were applied for 6 days and 12 weeks on the E-Band groups, and they did 180 repetitions a week for each exercise and 2160 repetitions in total for each exercise at the end of $12^{\text {th }}$ week (Table 2).

The comparison of the intergroup $\mathrm{PS}_{\text {(right-left, total), }} \mathrm{IL}_{\text {(right-left, total), }} \mathrm{QL}_{\text {(right-left, total) }}$ and $\mathrm{PS}+\mathrm{IL}+\mathrm{QL}_{(\text {total) }}$ muscle volumes of the research groups at the outset of the E-Band trainings (pre) and at the end of the E-Band trainings (post), which lasted for 12 weeks, was presented in Table 3. It was detected that there existed no statistically significant difference between the research groups in terms of posterior abdominal wall muscle volumes at the outset of the E-Band training ( $p>0.05$ ). At the end of the E-Band trainings, which lasted for 12 weeks, it was observed that $\mathrm{PS}_{\text {left, total }}, \mathrm{QL}_{\text {right, total }}$ muscle volumes of the men in the E-Band training group were greater than those of the men in the control group $(\mathrm{p}<0.05)$, and $\mathrm{IL}_{\text {right, left, total }}, \mathrm{QL}_{\text {right }}$ and $\mathrm{PS}+\mathrm{IL}+\mathrm{QL} \mathrm{L}_{\text {total }}$ muscle volumes of the womens in the E-Band training group were greater than those of the womens in the control group $(\mathrm{p}<0.05)$.

Table 3. Comparison of posterior abdominal wall muscle volumes in the research groups $\left(\mathrm{cm}^{3}\right)($ Mean \pm SD)

\begin{tabular}{|c|c|c|c|c|c|c|}
\hline \multirow[b]{2}{*}{ Muscles Groups } & \multicolumn{3}{|c|}{ Men } & \multicolumn{3}{|c|}{ Women } \\
\hline & $\begin{array}{c}\text { E-Band } \\
n=6\end{array}$ & $\begin{array}{c}\text { Control } \\
n=6\end{array}$ & $\mathbf{p}$ & $\begin{array}{c}\text { E-Band } \\
n=6\end{array}$ & $\begin{array}{c}\text { Control } \\
n=6\end{array}$ & $\mathbf{p}$ \\
\hline Pre-PS right & $265 \pm 34,2$ & $256 \pm 63,7$ & 0,770 & $172 \pm 18,9$ & $172 \pm 19,1$ & 0,980 \\
\hline Pre-PS left & $283 \pm 34,1$ & $258 \pm 60,8$ & 0,400 & $175 \pm 25,1$ & $174 \pm 20,9$ & 0,890 \\
\hline Pre-PS total & $548 \pm 68,1$ & $514 \pm 124,2$ & 0,570 & $347 \pm 43,6$ & $345 \pm 39,7$ & 0,930 \\
\hline Pre-IL rigt & $231 \pm 15,7$ & $243 \pm 36,2$ & 0,460 & $158 \pm 22,7$ & $153 \pm 20,8$ & 0,700 \\
\hline Pre-IL left & $212 \pm 21,8$ & $228 \pm 44,9$ & 0,440 & $147 \pm 20,1$ & $143 \pm 22,5$ & 0,750 \\
\hline Pre-IL total & $443 \pm 32,2$ & $472 \pm 80,2$ & 0,440 & $305 \pm 41,8$ & $296 \pm 42,8$ & 0,720 \\
\hline Pre-QL right & $70 \pm 9,6$ & $71 \pm 5,7$ & 0,910 & $47 \pm 6,9$ & $46 \pm 8,7$ & 0,850 \\
\hline Pre-QL left & $74 \pm 12,8$ & $76 \pm 14,9$ & 0,780 & $46 \pm 5,1$ & $51 \pm 9$ & 0,230 \\
\hline Pre-QL total & $144 \pm 22,2$ & $147 \pm 19,3$ & 0,820 & $92 \pm 10,4$ & $97 \pm 17,4$ & 0,590 \\
\hline Pre-PS+IL+QL total & $1135 \pm 89,1$ & $1132 \pm 205,1$ & 0,980 & $745 \pm 83,1$ & $738 \pm 57,9$ & 0,880 \\
\hline Post- PS right & $317 \pm 42$ & $262 \pm 47,5$ & 0,060 & $199 \pm 22,2$ & $176 \pm 19,2$ & 0,080 \\
\hline Post- PS left & $328 \pm 39,7$ & $256 \pm 47,3$ & $0,020 *$ & $195 \pm 22,2$ & $174 \pm 21,1$ & 0,120 \\
\hline Post- PS total & $645 \pm 80,2$ & $517 \pm 94,3$ & $\mathbf{0 , 0 3 0}$ * & $395 \pm 43,9$ & $350 \pm 40,2$ & 0,090 \\
\hline Post- IL right & $269 \pm 24,4$ & $251 \pm 39,8$ & 0,390 & $187 \pm 20,6$ & $154 \pm 21$ & $0,020 *$ \\
\hline Post- IL left & $258 \pm 22,8$ & $247 \pm 47,6$ & 0,610 & $184 \pm 23,9$ & $151 \pm 23,6$ & $0,040 *$ \\
\hline Post- IL total & $527 \pm 46,3$ & $498 \pm 87$ & 0,49 & $371 \pm 42,7$ & $306 \pm 43,6$ & $0,020 *$ \\
\hline Post- QL right & $90 \pm 8,6$ & $76 \pm 9,3$ & $\mathbf{0 , 0 2 *}$ & $61 \pm 10,2$ & $48 \pm 9,7$ & $0,049 *$ \\
\hline Post- QL left & $95 \pm 11,5$ & $78 \pm 17,3$ & 0,07 & $61 \pm 6,5$ & $53 \pm 8,3$ & 0,100 \\
\hline Post- QL total & $185 \pm 19,8$ & $154 \pm 25,7$ & $\mathbf{0 , 0 4 *}$ & $122 \pm 15,6$ & $102 \pm 17,7$ & 0,060 \\
\hline Post- PS+IL+QL total & $1357 \pm 126,9$ & $1169 \pm 193,5$ & 0,07 & $888 \pm 85,2$ & $757 \pm 66$ & $0,010 *$ \\
\hline
\end{tabular}

PS: m. psoas, IL: m. iliacus, QL: m. quadratus lumborum, ${ }^{*} \mathrm{p}<0,05,{ }^{*} \mathrm{p}<0,001$

Pre: Before the E-Band training, Post: After the E-Band training.

The comparison of increases in $\mathrm{PS}_{\text {(right, left, total) }} \mathrm{IL}_{\text {(right, left, total), }} \mathrm{QL}_{\text {(right, left, total) }}$ and $\mathrm{PS}+\mathrm{IL}+\mathrm{QL}_{\text {(total) }}$ muscle volumes of the E-Band and the control groups at the outset and after the 12-week E-Band training was presented in Table 4. Great

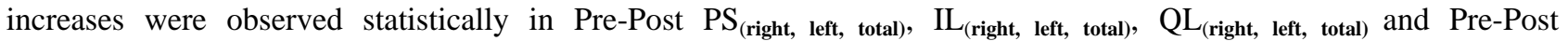
$\mathrm{PS}+\mathrm{IL}+\mathrm{QL}_{(\text {total) }}$ muscle volumes of E-Band men and women groups. A significant increase was detected in Pre-Post $\mathrm{IL}_{\text {(left), }} \mathrm{QL}_{\text {(right, total) }}$ muscle volumes of the men in the control group and in Pre-Post $\mathrm{PS}_{\text {(right) }}, \mathrm{IL}_{\text {(right, left, total), }} \mathrm{QL}_{\text {(right, left, }}$ total) and $\mathrm{PS}+\mathrm{IL}+\mathrm{QL}_{(\text {total }}$ muscle volume values of the women in the control group. 
Table 4. The comparison of the increase in PS, IL, QL muscle volumes of the research groups $\left(\mathrm{cm}^{3}\right)($ Mean \pm SD)

\begin{tabular}{|c|c|c|c|c|c|c|c|c|c|c|c|c|}
\hline \multirow{3}{*}{$\begin{array}{c}\text { MUSCLES } \\
\text { GROUPS }\end{array}$} & \multicolumn{6}{|c|}{ MEN } & \multicolumn{6}{|c|}{ WOMEN } \\
\hline & \multicolumn{3}{|c|}{ Paired Differences } & \multicolumn{9}{|c|}{ Paired Differences } \\
\hline & Mean & SD & SE & t & df & $\mathbf{P}$ & Mean & SD & SE & $\mathbf{t}$ & df & $\mathbf{P}$ \\
\hline $\begin{array}{l}\text { Pre-PS right } \\
\text { Post- PS right }\end{array}$ & 52 & 13,4 & 5,5 & $-9,485$ & 5 & $0,001 * *$ & 27 & 4,6 & 1,9 & $-14,519$ & 5 & $0,001 * *$ \\
\hline $\begin{array}{l}\text { Pre- PS left } \\
\text { Post- PS left }\end{array}$ & 45 & 12,4 & 5,1 & $-8,923$ & 5 & $0,001 * *$ & 20 & 4,7 & 1,9 & $-10,349$ & 5 & $0,001 * *$ \\
\hline $\begin{array}{l}\text { Pre-PS total } \\
\text { Post- PS total }\end{array}$ & 97 & 22,8 & 9,3 & $-10,435$ & 5 & $0,001 * *$ & 47 & 3,6 & 1,5 & $-31,922$ & 5 & $0,001 * *$ \\
\hline $\begin{array}{l}\text { Pre- IL right } \\
\text { Post-IL right }\end{array}$ & 38 & 12,1 & 4,9 & $-7,627$ & 5 & $0,001 * *$ & 29 & 4,9 & 2 & $-14,830$ & 5 & $0,001 * *$ \\
\hline $\begin{array}{l}\text { Pre- IL left } \\
\text { Post- IL left } \\
\end{array}$ & 46 & 18,9 & 7,7 & $-5,960$ & 5 & $0,002^{*}$ & 37 & 9,4 & 3,8 & $-9,719$ & 5 & $0,001 * *$ \\
\hline $\begin{array}{l}\text { Pre-IL total } \\
\text { Post- IL total }\end{array}$ & 84 & 29,3 & 12 & $-6,997$ & 5 & $0,001 * *$ & 67 & 11,8 & 4,8 & $-13,871$ & 5 & $0,001 * *$ \\
\hline $\begin{array}{l}\text { Pre- QL right } \\
\text { Post-QL right }\end{array}$ & 20 & 2 & 0,8 & $-24,434$ & 5 & $0,001 * *$ & 14 & 4,1 & 1,7 & $-8,433$ & 5 & $0,001 * *$ \\
\hline $\begin{array}{l}\text { Pre- QL left } \\
\text { Post- QL left }\end{array}$ & 22 & 5,8 & 2,4 & $-9,197$ & 5 & $0,001 * *$ & 15 & 4,9 & 2 & $-7,716$ & 5 & $0,001 * *$ \\
\hline $\begin{array}{l}\text { Pre-QL total } \\
\text { Post- QL total } \\
\end{array}$ & 41 & 5,6 & 2,3 & $-18,102$ & 5 & $0,001 * *$ & 30 & 7,8 & 3,2 & $-9,310$ & 5 & $0,001 * *$ \\
\hline $\begin{array}{l}\text { Pre-PS+IL+QL } \\
\text { total } \\
\text { Post- } \\
\text { PS+IL+QLtotal }\end{array}$ & 223 & 42,2 & 17,2 & $-12,917$ & 5 & $0,001 * *$ & 143 & 10,3 & 4,2 & $-34,147$ & 5 & $0,001 * *$ \\
\hline $\begin{array}{l}\text { Pre-PS right } \\
\text { Post- PS right }\end{array}$ & 6 & 26,6 & 10,9 & $-0,506$ & 5 & 0,634 & 4 & 2,8 & 1,1 & $-3,522$ & 5 & $0,017^{*}$ \\
\hline $\begin{array}{l}\text { Pre- PS left } \\
\text { Post- PS left }\end{array}$ & 2 & 26,4 & 10,8 & 0,208 & 5 & 0,844 & 0,5 & 2,5 & 1 & $-0,456$ & 5 & 0,667 \\
\hline $\begin{array}{l}\text { Pre-PS total } \\
\text { Post- PS total }\end{array}$ & 3 & 52,5 & 21,4 & $-0,152$ & 5 & 0,885 & 4 & 4,5 & 1,8 & $-2,456$ & 5 & 0,058 \\
\hline $\begin{array}{l}\text { Pre- IL right } \\
\text { Post-IL right }\end{array}$ & 8 & 12,1 & 4,9 & $-1,622$ & 5 & 0,166 & 1 & 0,8 & 0,3 & $-3,988$ & 5 & $0,010^{*}$ \\
\hline $\begin{array}{l}\text { Pre- IL left } \\
\text { Post- IL left }\end{array}$ & 18 & 17 & 6,9 & $-2,657$ & 5 & $0,045^{*}$ & 9 & 7,2 & 3 & $-2,894$ & 5 & $0,034^{*}$ \\
\hline $\begin{array}{l}\text { Pre-IL total } \\
\text { Post- IL total }\end{array}$ & 26 & 28 & 11,4 & $-2,310$ & 5 & 0,069 & 10 & 7,1 & 2,9 & $-3,428$ & 5 & $0,019 *$ \\
\hline $\begin{array}{l}\text { Pre- QL right } \\
\text { Post-QL right }\end{array}$ & 5 & 4,2 & 1,7 & $-2,999$ & 5 & $0,030^{*}$ & 3 & 1,2 & 0,5 & $-5,257$ & 5 & $0,003 *$ \\
\hline $\begin{array}{l}\text { Pre- QL left } \\
\text { Post- QL left }\end{array}$ & 2 & 3,5 & 1,4 & $-1,404$ & 5 & 0,219 & 2 & 1,3 & 0,5 & $-3,972$ & 5 & $0,011^{*}$ \\
\hline $\begin{array}{l}\text { Pre-QL total } \\
\text { Post- QL total }\end{array}$ & 7 & 6,5 & 2,7 & $-2,701$ & 5 & $0,043^{*}$ & 5 & 1,1 & 0,4 & $-10,690$ & 5 & $0,001 * *$ \\
\hline $\begin{array}{l}\text { Pre-PS+IL+QL } \\
\text { total } \\
\text { Post- } \\
\text { PS+IL+QLtotal }\end{array}$ & 37 & 81,1 & 33,1 & $-1,112$ & 5 & 0,317 & 19 & 9,7 & 3,9 & $-4,858$ & 5 & $0,005^{*}$ \\
\hline
\end{tabular}

PS: m. psoas, IL: m. iliacus, QL: m. quadratuslumborum, ${ }^{*} \mathrm{p}<0,05,{ }^{* *} \mathrm{p}<0,001$,

Pre: Before the E-Band training, Post: After the E-Band training.

The comparison of the maximal weights that the men-women E-Band and control groups lifted in snatch, clean-and-jerk, and total at the outset of the E-Band trainings and at the end of E-Band trainings, which lasted for 12 weeks, was presented in Table 5. No statistically significant difference was observed between the men-women E-Band and control groups in terms of the parameters at the outset and end of the E-Band training ( $>0,05)$. 
Table 5. The comparison of the weights that the research groups lifted in snatch, clean-and-jerk, and total (kg) $($ Mean \pm SD).

\begin{tabular}{|c|c|c|c|c|c|c|}
\hline \multirow{3}{*}{ Weightlifting Techniquies } & \multicolumn{3}{|c|}{ Men } & \multicolumn{3}{|c|}{ Women } \\
\hline & E-Band & Control & \multirow{2}{*}{ p } & E-Band & Control & \multirow[b]{2}{*}{$\mathbf{p}$} \\
\hline & $n=6$ & $n=6$ & & $n=6$ & $n=6$ & \\
\hline Pre-Snatch & $92,5 \pm 18,6$ & $93,3 \pm 23,1$ & 0,950 & $65 \pm 6,3$ & $70,7 \pm 15,4$ & 0,420 \\
\hline Pre-Clean and Jerk & $113,3 \pm 22,1$ & $115,2 \pm 27$ & 0,900 & $84,8 \pm 9,9$ & $87,7 \pm 19,9$ & 0,760 \\
\hline Pre- Total & $205,8 \pm 40,2$ & $208,5 \pm 50$ & 0,920 & $149,8 \pm 15,8$ & $158,3 \pm 35,1$ & 0,600 \\
\hline Post Snatch & $97,3 \pm 18,8$ & $94,2 \pm 23$ & 0,8 & $68,7 \pm 5,6$ & $71,3 \pm 15,6$ & 0,700 \\
\hline Post-Clean and Jerk & $118 \pm 21,9$ & $116,3 \pm 27,7$ & 0,91 & $89 \pm 10,1$ & $88,3 \pm 19,1$ & 0,940 \\
\hline Post- Total & $215,3 \pm 40,3$ & $210,5 \pm 50,6$ & 0,86 & $157,7 \pm 15,4$ & $159,7 \pm 34,4$ & 0,900 \\
\hline
\end{tabular}

$* \mathrm{p}<0,05, * * \mathrm{p}<0,001$, Pre: Before the E-Band training, Post: After the E-Band training.

The comparison of the increases in maximal weights that the research groups lifted in snatch, clean-and-jerk, and total at the outset of the 12-week E-Band trainings (pre) and at the end of E-Band trainings (post) was presented in Table 6. Differences were detected statistically in the groups' maximal weightlifting at the outset and end of the E-Band training in Pre-Post snatch, clean-and-jerk, and total (Except for the maximal weights that the women in the control group lifted in Pre-Post snatch, clean-and-jerk).

Table 6. The comparison of the increases in maximal weights that the research groups lifted in snatch, clean-and-jerk, and total $(\mathrm{kg})($ Mean $\pm \mathrm{SD})$

\begin{tabular}{|c|c|c|c|c|c|c|c|c|c|c|c|c|c|}
\hline & \multirow{3}{*}{$\begin{array}{c}\text { WEIGHTLIFTING } \\
\text { TECHNIQUIES }\end{array}$} & \multicolumn{6}{|c|}{ MEN } & \multicolumn{6}{|c|}{ WOMEN } \\
\hline & & \multicolumn{3}{|c|}{ Paired Differences } & \multirow{2}{*}{$\mathbf{t}$} & \multirow{2}{*}{ df } & \multirow{2}{*}{$\mathbf{p}$} & \multicolumn{3}{|c|}{ Paired Differences } & \multirow{2}{*}{$\mathbf{t}$} & \multirow{2}{*}{ df } & \multirow{2}{*}{$\mathbf{p}$} \\
\hline & & Mean & SD & SE & & & & Mean & SD & SE & & & \\
\hline \multirow{3}{*}{ 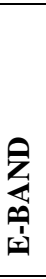 } & $\begin{array}{l}\text { Pre-Snatch } \\
\text { Post Snatch }\end{array}$ & 4,8 & 1,2 & 0,5 & $-10,127$ & 5 & $0,001 * *$ & 3,7 & 1,6 & 0,7 & $-5,129$ & 5 & $0,004 *$ \\
\hline & $\begin{array}{l}\text { Pre-Clean and Jerk } \\
\text { Post-Clean and } \\
\text { Jerk }\end{array}$ & 4,7 & 1,6 & 0,7 & $-7,000$ & 5 & $0,001 * *$ & 4,2 & 0,4 & 0,2 & $-25,000$ & 5 & $0,001 * *$ \\
\hline & $\begin{array}{l}\text { Pre- Total } \\
\text { Post- Total }\end{array}$ & 9,5 & 1,9 & 0,8 & $-12,438$ & 5 & $0,001 * *$ & 7,8 & 1,6 & 0,7 & $-11,977$ & 5 & $0,001 * *$ \\
\hline \multirow{3}{*}{ 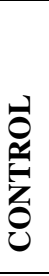 } & $\begin{array}{l}\text { Pre-Snatch } \\
\text { Post Snatch }\end{array}$ & 0,8 & 0,8 & 0,3 & $-2,712$ & 5 & $0,042^{*}$ & 0,7 & 0,8 & 0,3 & $-2,000$ & 5 & 0,102 \\
\hline & $\begin{array}{l}\text { Pre-Clean and Jerk } \\
\text { Post-Clean and } \\
\text { Jerk }\end{array}$ & 1,2 & 1,0 & 0,4 & $-2,907$ & 5 & $0,034^{*}$ & 0,7 & 0,8 & 0,3 & $-2,000$ & 5 & 0,102 \\
\hline & $\begin{array}{l}\text { Pre- Total } \\
\text { Post- Total }\end{array}$ & 2,0 & 1,3 & 0,5 & $-3,873$ & 5 & $0,012^{*}$ & 1,3 & 1 & 0,4 & $-3,162$ & 5 & $0,025^{*}$ \\
\hline
\end{tabular}

$* \mathrm{p}<0,05, * * \mathrm{p}<0,001$, Pre: Before the E-Band training, Post: After the E-Band training.

\section{Discussion}

It was reported that different training methods and sports equipment were used to improve muscular force, trainings that were applied had positive effects on muscle cross-sectional areas and volumes, these effects contributed positively on both the performance and health of the athletes and the rehabilitation of individuals who do not exercise regularly (Mendis et al., 2016; Hoshikawa et al., 2013; Jelena et al., 2009). It was reported that in a study which was conducted by separating young male soccer players (12-13 years) into exercise and control groups, both groups were made to perform soccer training, and in addition to the soccer trainings the individuals in the exercise group were made to perform stabilization exercises (elbow-toe, elbow-heel, side bridge, modified 1-legged squat, and bent-knee push-up) four days a week for 6 months. In the study in which MR images of the groups were used, it was reported that there occurred no increase in the m.rectus abdominus, $\mathrm{m}$. oblique (internal oblique, external oblique, and transversus abdominis), m. psoas major, m. quadratus lumborum, and m. erector spinae cross-sectional areas of the trunk muscles after the stabilization exercises (Hoshikawa et al., 2013). In another study conducted with the athletes, it was revealed that motor control trainings (using pilates exercises and elastic band) that were applied on elite men football players $(22.8 \pm 3.5 \mathrm{age})$ for 15 weeks in addition to the football trainings during the season provided an increase in iliopsoas, sartorius and gluteus medius muscle cross-sectional areas, and this increase reduced the back pains (Mendis and Hides, 2013). Jelena et al. (2009) applied elbow extensor training on healthy men individuals ( $22.5 \pm 3.7$ years $)$ who had not done exercise before using isoacceleration dynamometry equipment for 6 weeks (5 days a week, 5 sets and 10 repetitions). It 
was revealed that the applied training increased both two arms triceps brachii muscle volume (right arm from $456.9 \pm 113.8$ $\mathrm{cm}^{3}$ to $475.8 \pm 100.9 \mathrm{~cm}^{3}$, left arm from $444.3 \pm 121.9 \mathrm{~cm}^{3}$ to $468.4 \pm 110.4 \mathrm{~cm}^{3} \mathrm{p}<0.05$ ) and upper arm extensor muscular force $(43 \% \mathrm{p}<0.01)$. It was reported that a statistically powerful positive correlation was detected between the increase in triceps brachii muscle volume and the increase in muscular force ( $\mathrm{p}<0.01)$. In another study in which young men individuals $(23.0 \pm 1.7$ years) were separated into exercise and control groups, the individuals in the exercise group were made to do short-time ( $15 \mathrm{~min}$ ) trainings with electrically braked bicycle ergometer at low intensity ( $40 \%$ of VO2 max) and 3 days a week for 8 weeks; and any training program was not applied to the individuals in the control group. It was reported that in determining muscle volumes on MR images, there occurred an increase in thigh (3.8\%) and quadriceps femoris $(5.1 \%)$ muscle volumes of the individuals in the exercise group $(\mathrm{p}<0.01)$, and no change was observed in the individuals in the control group $(p>0.01)$. It was revealed that maximal isometric knee extension force $(7.7 \%, p<0.1)$ and aerobic capacity increased positively together with the increase in muscle volumes of the individuals in the exercise group (Abe et al., 2010). Harber et al. (2009) reported that the 12-week aerobic exercise trainings (using electronically braked bicycle ergometer) that they applied to the old women ( $71 \pm 2$ years) increased the quadriceps femoris muscle volumes of the old women (From $587 \pm 55 \mathrm{~cm}^{3}$ to $654 \pm 60 \mathrm{~cm}^{3} \mathrm{p}<0.05$ ), this increase in the muscle volume enhanced the knee extensor power (From $241 \pm 42 \mathrm{~W}$ to $296 \pm 45 \mathrm{~W}$ ) and isometric force parameters (From $199 \pm 25 \mathrm{Nm}$ to $261 \pm 27 \mathrm{Nm}$ ) to maximal levels. In another study conducted with the old individuals (70-82 years, male) Morse et al. (2005) reported that the resistance exercise trainings (Leg press and sitting calf exercise with body building equipment, leg press sitting plantar flexion exercises with elastic band) that were applied for 12 months 3 days a week increased the triceps surae muscle volumes of the old individuals by $12 \%$ (from $796.3 \pm 78.9 \mathrm{~cm}^{3}$ to $916.8 \pm 144.4 \mathrm{~cm}^{3} \mathrm{P}<0.05$ ), and isometric plantar flexor contraction torque by $20 \%$ (from $113.1 \pm 22.0 \mathrm{Nm}$ to $141.5 \pm 19.2 \mathrm{Nm}$ p $<0.01)$. It was revealed that an increase in the triceps surae muscle volume of affects muscle activation and muscular force positively. In a study in which rectus abdominis, transversus and obliquesabdominis muscle volumes were detected on MR images of before and after the exercise at the end of a 36-week Pilates training that was applied to middle-age women ( $35 \pm 5.4$ years) who had never done exercise before, it was reported that pilates trainings increased rectus abdominis muscle volume by $21 \%(\mathrm{P}<0.05)$, and dominant side obliques and transversusabdominis muscle volume by $8 \%(\mathrm{P}<0.05)$. It was stated that long-term pilates trainings were useful in strengthening abdominal muscles and preventing asymmetrical abdominal muscle development (Dorado et al., 2012).

In our study, significant increases were detected in posterior abdominal wall muscle volumes of the men and women athletes in the exercise group that we applied E-Band training for 12 weeks. An increase of respectively 52 $\pm 13,4$, $45 \pm 12,4,97 \pm 22,8 \mathrm{~cm}^{3}$ was observed in the Pre-Post PS (right, left, total) muscle volumes of the males in the E-Band group,

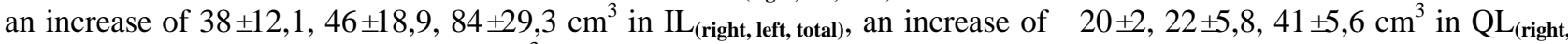
left, total), and an increase of $223 \pm 42,2 \mathrm{~cm}^{3}$ in PS+IL+QL (total) muscle volumes. In the E-Band women groups, an increase of respectively $27 \pm 4,6,20 \pm 4,7,47 \pm 3,6 \mathrm{~cm}^{3}$ was detected in the Pre-Post $\mathrm{PS}_{\text {(right, left, total) }}$ muscle volumes, and an increase of $29 \pm 4,9,37 \pm 9,4,67 \pm 11,8 \mathrm{~cm}^{3}$ in $\mathrm{IL}_{\text {(right, left, total), }}$ an increase of $14 \pm 4,1,15 \pm 4,9,30 \pm 7,8 \mathrm{~cm}^{3}$ in $\mathrm{QL}_{\text {(right, left, total) }}$, and an increase of $143 \pm 10,3 \mathrm{~cm}^{3}$ in $\mathrm{PS}+\mathrm{IL}+\mathrm{QL}_{\text {(total }}$ muscle volumes. We think that the increases in posterior abdominal wall muscle volumes observed in the men and women exercise groups were caused by the hypertrophic effects of the E-Band trainings, which were applied for 12 weeks, on these muscles. In our study, increases in PS, IL, $\mathrm{QL}_{\text {(right, left, total) }}$ muscle volumes of the men and the women athletes in the control group were also observed but it was detected that these increases were much smaller than the increases in the volumes in the E-Band groups. We think that this difference observed between the posterior abdominal wall muscle volumes of the E-Band and the control groups arised from the fact that only weight lifting trainings were applied to the athletes in the control group and these weight lifting trainings did not work these muscles actively.

Different training methods with different equipment were applied to various training groups and it was concluded that the trainings provided an increase in the muscle volumes of the individuals and this increase affected muscular force and power parameters of the individuals positively (Jelena et al., 2009; Abe et al., 2010; Harber et al., 2009; Ince 2019; Morse et al., 2005). In our study, increases were detected in one-repetition maximal weights that the men and women athletes lifted in the E-Band group at the outset of E-Band training and at the end of 12 weeks. An increase of respectively 4,8 $\pm 1,2$,

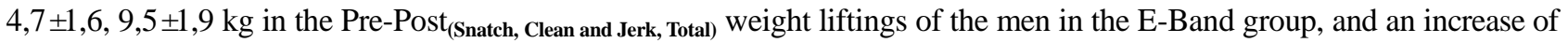

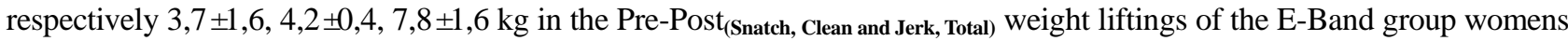
were observed. Increases were also observed in the weights that the athletes in the control group lifted in snatch, clean-and-jerk, and total, but these increases were much smaller than those of the athletes in the E-Band group. In our study, we think that the differences between the increases in weights that the athletes in the E-Band and the control groups lifted in snatch, and clean and jerk arose from the differences in increases that occurred in posterior abdominal wall muscle volumes between the groups. Also, it was reported that as the E-Bands have a feature that they can make the applied movements felt from every angle, they contribute much to force development and the improvement of other motoric features (Page and Ellenbecker, 2005). Also in our study, it is thought that E-Band had positive effects on sportive performances of the athletes in the E-Band group because of the angular advantages of E-Band on the exercises that were applied. 
In conclusion, it was observed that elastic band trainings that were applied to Olympic weightlifters created positive effects on their sportive performances as well as they increased the PS, IL, QL muscle volumes of the athletes. Based on this result, it has been concluded that in order for Olympic weightlifters to contribute to their sportive achievements in national and international competitions, it might be a correct approach to add specific elastic band exercises that can improve posterior abdominal wall muscles to general weight lifting programs.

\section{References}

Abe, T., Fujita, S., Nakajima, T., Sakamaki, M., Ozaki, H., Ogasawara, R., ... Ishii, N. (2010). Effects of low-intensity cycle training with restricted leg blood flow on thigh muscle volume and VO2max in young men. Journal of Sports Science and Medicine, 9, 452-458.

Andersson, E., Oddsson, L., Grundström, H., \& Thorstensson, A. (2007). The role of the psoas and iliacus muscles for stability and movement of the lumbar spine, pelvis and hip. Scandinavian Journal of Medicine \& Science in Sports, 5(1), 10-16. https://doi.org/10.1111/j.1600-0838.1995.tb00004.x

Arınc1, K., \& Elhan, A. (2001). Anatomy. Ankara: Güneş Kitapevi, 173-202 p.

Badıllo, J., Izquierdo, M., \& Gorostiaga, M. (2006). Moderate volume of high relative trainning intensity produces greater strenght gains compared with low and high volumes in competitive weightlifters. Journal of Strength and Conditioning Research, 20(1), 73-81. https://doi.org/10.1519/00124278-200602000-00012

Bahar, S., Bolat, D., Dayan, M. O., \& Paksoy, Y. (2014). Two-and three-dimensional anatomy of paranasal sinuses in Arabian foals. $J$ Vet Med Sci, 76(1), 37-44, Available at: https://doi.org/10.1292/jvms.13-0172

Bogduk, N., Pearcy, M., \& Hadfield, G. (1992). Anatomy and biomechanics of psoas major. Clin Biomech, 7(2), 109-119. https://doi.org/10.1016/0268-0033(92)90024-X

Canan, S., Şahin B., Odacı, E., Ünal, B., Aslan H., Bilgiç, S., \& Kaplan, S. (2002). A stereological method used in the calculation of total volume, volume density and volume ratios: Cavalieri princible. Türkiye Klinikleri J Med Sci, 22, $7-14$.

Dorado, C., Calbet, J.C., Gordillo, A., Alayon S., \& Moysi, J. S. (2012). Marked effects of pilates on the abdominal muscles: a longitudinal magnetic resonance imaging study. Medicine \& Science in Sports \& Exercis, 44(8), 1589-1594. https://doi.org/10.1249/MSS.0b013e31824fb6ae

Garhammer, J. (1985). Biomechanical profiles of Olympic weightlifters. Int J Sport Biomech, 1(2), 122-130. https://doi.org/10.1123/ijsb.1.2.122

Garhammer, J. (1991). Comparison of maximal power outputs between elite male and female weightlifters in competition. Int J Sport Biomech, 7(1), 3-11, Available at: https://doi.org/10.1123/ijsb.7.1.3

Greene, H. S., Cholewicki, J., Galloway, M. T., Nguyen, C. V., \& Radebold, A. (2001). A history of low back injury is a risk factor for recurrent back injuries in varsity athletes. Am J Sports Med, 29(6), 795-800. https://doi.org/10.1177/03635465010290062001

Gundersen, H. J., \& Jensen, E. B. (1987). The efficiency of systematic sampling in stereology and its prediction. $J$ Microsc, 147(3), 229-263, https://doi.org/10.1111/j.1365-2818.1987.tb02837.x

Gündüz, N, (1997). Antrenman bilgisi, İzmir, Saray Kitapevleri, 1-75 p.

Harber, M. P., Konopka, A. R., Douglass, M. D., Minchev, K., Kaminsky, L. A., Todd, A., Trappe, K. T., \& Trappe, S. (2009). Aerobic exercise training improves whole muscle and single myofiber size and function in older women. Am J Physiol Regul Integr Comp Physiol, 297(5), 1452-1459. https://doi.org/10.1152/ajpregu.00354.2009

Hintermeister, R. A., Lange, G. W., Schultheis, J. M., Bey M. J., \& Hawkins, R. J. (1998). Electromyographic activity and applied load during shoulder rehabilitation exercises using elastic resistance. The American Journal of Sports Medicine, 26(2), 210-220. https://doi.org/10.1177/03635465980260021001

Hoshikawa, Y., Iida, T., Muramatsu, M., Ii, N., Nakajima, Y., Chumank, K., \& Kanehisa, H. (2013). Effects of stabilization training on trunk muscularity and physical performances in youth soccer players. J Strength Cond Res, 27(11), 3142-3149. https://doi.org/10.1519/JSC.0b013e31828bed36

İnce, İ. (2019). Effects of Split Style Olympic Weightlifting Training on Leg Stiffness Vertical Jump Change of Direction and Sprint in Collegiate Volleyball Players. Universal Journal of Educational Research, 7(1), 24-31. https://doi.org/10.13189/ujer.2019.070104

Janusevicius, D., Snieckus, A., Skurvydas, A., Silinskas, V., Trinkunas, E., Cadefau, J. A., \& Kamandulis, S. (2017). Effects of high velocity elastic band versus heavy resistance training on hamstring strength, activation, and sprint running performance. Journal of Sports Science and Medicine, 16, 239-246. 
Jelena, Z., Popadic, G., Dusko, B. K., Natasa, R. D., Djordje, G. J., David, A. B., \& Nikola, G. G. (2009). Changes of functional status and volume of triceps brachii measured by magnetic resonance imaging after maximal resistance training. Journal of Magnetıc Resonance Imagin, 29(3), 671-676. https://doi.org/10.1002/jmri.21690

Jemmett, R. S., Macdonald, D. A., \& Agur, A. M. R. (2004). Anatomical relationships between selected segmental muscles of the lumbar spine in the context of multi-planar segmental motion: a preliminary investigation. Man Ther, 9(4), 203-210. https://doi.org/10.1016/j.math.2004.07.006

Johnson, C., \& Reid, J. G. (1991). Lumbar compressive and shear forces during various trunk curl-up exercises. Clinical Biomechanics, 6(2), 97- 104. https://doi.org/10.1016/0268-0033(91)90006-C

Johnston, C. A. M., David, M. L., \& Wiley, J. P. (1999). Treatment of lliopsoas syndrome with a hip rotation strengthening program: a retrospective case series. Journal of Orthopaedic \& Sports Physical Therapy, 29(4), 218-224. https://doi.org/10.2519/jospt.1999.29.4.218

Kwak, C. J., Kim, Y. L., \& Lee, S. M. (2016). Effects of elastic-band resistance exercise on balance, mobility and gait function, flexibility and fall efficacy in elderly people. The Journal of Physical Therapy Science, 28, 3189-3196, https://doi.org/10.1589/jpts.28.3189

McGill, S., Juker, D., \& Kropf, P. (1996). Quantitative İntramusculer myoelectric activity of quadratus lumborum during a wide variety of tasks. Clin Biomech, 11(3), 170-172. https://doi.org/10.1016/0268-0033(95)00056-9

Mendis, M. D., \& Hides, J. A. (2016). Effect of motor control training on hip muscle in elite football players with and without low back pain. Journal of Science and Medicine in Sport, 19(11), 866-871 https://doi.org/10.1016/j.jsams.2016.02.008

Mikesky, A. E., Topp, R., Wigglesworth, J. K., Harsha, D. M., \& Edwards, J. E. (1994). Efficacy of a home-based training program for older adults using elastic tubing. Eur $J$ Appl Physiol, 69(4), 316-320. https://doi.org/10.1007/BF00392037

Morse, C. I., Thom, J. M., Mian, O. S., Muirhead, A., Birch, K. M., \& Narici, M. V. (2005). Muscle strength, volume and activation following 12-month resistance training in 70-year-old males. Eur J Appl Physiol, 95(2-3), 197-204, https://doi.org/10.1007/s00421-005-1342-3

Nachemson, A. (1966). Electromyographic studies on the vertebral portion of the psoas muscle; with special reference to its stabilizing function of the lumbar spine. Acta Orthop Scand, 37(2), 177-190. https://doi.org/10.3109/17453676608993277

Oh, S. L., Kim, H., Woo, S., Cho, B. L., Song, M., Park, Y. H., Lim, Y. Y., \& Song, W. (2016). Effects of an integrated health education and elastic band resistance training program on physical function and muscle strength in community-dwelling elderly women: Healthy Aging and Happy AgingII study. Japan Geriatrics Society, 17(5), 825-833. https://doi.org/10.1111/ggi.12795

Page, P., \& Ellenbecker, T. (2005). Strenght band training. Human Kinetics, 2005; 3-91 p.

Sahin, B., Emirzeoglu, M., Uzun, A., Incesu, L., Bek, Y., Bilgic, S., \& Kaplan, S. (2003). Unbiased estimation of the liver volume by the Cavalieri principle using magnetic resonance images. Eur J Radiol, 47(2), 164-170. https://doi.org/10.1016/S0720-048X(02)00152-3

Santos, G. M., Tavares, G. M. S., Gasperi, G., \& Bau, G. (2009). Mechanical evaluation of the resistance of elastic bands. Rev Bras Fisioter, 13(6), 521-526. https://doi.org/10.1590/S1413-35552009000600009

Treiber, F. A., Lott, J., Duncan, J., Slavens, G., \& Davis, H. (1998). Effects of Theraband and lightweight dumbbell training on shoulder rotation torque and serve performance in college tennis players. The American Journal of Sports Medicine, 26(4), 510-515. https://doi.org/10.1177/03635465980260040601

Williams, P., \& Warwick, R. (1992). Anatomy the gray's. Edimburg: Churchill Livingstone, 633-634 p.

Yasuda, T., Kazuya Fukumura, K., Uchida, Y., Koshi, H., Iida, H., Masamune, K., ... Nakajima, T. (2014). Effects of low-load, elastic band resistance training combined with blood flow restriction on muscle size and arterial stiffness in older adults. Journals of Gerontology: biological sciences, 70(8), 950-958.

https://doi.org/10.1093/gerona/glu084

\section{Copyrights}

Copyright for this article is retained by the author(s), with first publication rights granted to the journal.

This is an open-access article distributed under the terms and conditions of the Creative Commons Attribution license which permits unrestricted use, distribution, and reproduction in any medium, provided the original work is properly cited. 